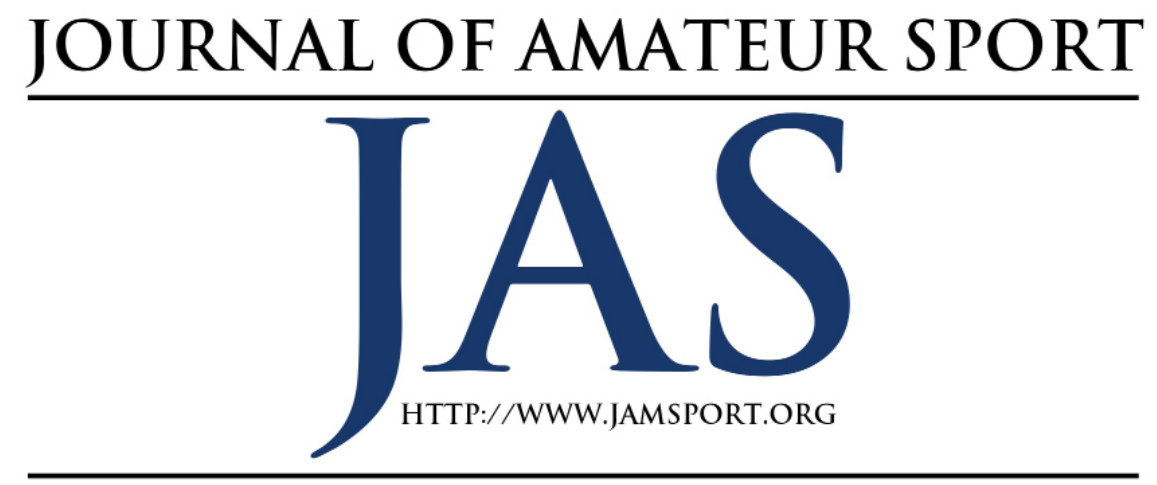

\title{
A Mixed-Methods Approach to Identifying Administration Issues Pertinent in Interscholastic Sports
}

\author{
Eric W. Forsyth ${ }^{1}$ \\ James E. Johnson ${ }^{2}$ \\ Michael Fraina ${ }^{4}$
}

\author{
Warren A. Whisenant ${ }^{3}$ \\ Gibson W. Stoffer ${ }^{2}$
}

\author{
${ }^{1}$ Bemidji State University \\ ${ }^{2}$ Ball State University \\ ${ }^{3}$ University of Miami \\ ${ }^{4}$ Farmingdale State College
}

The purpose of this study was to investigate three propositions: a) What are the administration issues most pertinent to interscholastic sport today, as well as the next five years?, b) How important are those administration issues to athletic administrators?, and c) What are the potential implications of those pertinent administration issues to practicing athletic administrators? The literature provides a general overview of relevant issues surrounding interscholastic athletics. However, the importance and implications of relevant issues to practicing high school athletic administrators are difficult to discern. To answer the first proposition, the Minnesota State High School League (MSHSL) provided 10 contemporary administration issues that were most pertinent to interscholastic sport today, as well as the next five years. To answer the second proposition, a Likert-Scale was created so that practicing athletic administrators could rate each issue on a scale of $5=$ extremely important to $1=$ very little importance. A national study was conducted with athletic directors from the National Interscholastic Athletic Administrators Association $(\mathrm{N}=170)$ annual conference. A one-tailed ANOVA was executed to determine significant differences among the 10 administration issues identified by the MSHSL. Four issues were found to be significant; Athletic Facilities, Athletic Training, Health Issues and Travel Teams. A Games-Howell post hoc was executed to determine significant differences across geographical regions of the United States. For the third proposition, semi-structured interviews were completed to provide insight on the implications for practicing athletic administrators. The results offer insight from which further investigations could be conducted to continue building on policies that influence interscholastic athletic administrators' day-to-day accountability when overseeing their athletic programs. 


\section{Introduction}

$\left\{\begin{array}{l}\text { ccording to the National Federa- } \\ \text { tion of State High School Asso- } \\ \text { ciations (NFHS), there are more }\end{array}\right.$ than 24,000 high schools throughout the United States and Canada, employing in excess of 300,000 administrators and coaches, including nearly eight million male and female athletes that compete in interscholastic sport competitions (Forsyth, Martin, \& Whisenant, 2018; NFHS, 2018). The sheer numbers of interscholastic sport stakeholders earn this context consideration as the "single most significant dimension" (Robinson, Hums, Crow $\&$ Philips, 2001, p.21) in the entire sport enterprise (Forsyth et al., 2018; Forsyth \& Olson, 2013; Whisenant \& Forsyth, 2011; Whisenant, Forsyth \& Martin, 2014).

Despite the economic and sociological impact that interscholastic sports has had on North America, the body of research focused on this segment of sport is scarce. When comparing the number of articles published in academic journals regarding Olympic, professional, and collegiate sport, interscholastic sport has fallen well behind. More specifically, although studies have addressed the context of interscholastic sport, none have focused upon administrative issues that impact local, state, and national high school athletic associations. Based on this gap in literature, this study seeks to quantitatively and qualitatively explore perspectives of interscholastic administrators as to significant issues that they regularly encounter. Completion of this study is beneficial not only for the high school athletic administrators, but by extension coaches, parents, and athletes. If athletic directors/administrators are able to more conclusively identify the salient issues involving their programs, they can improve sport programming.

The authors reviewed eight sport management academic journals based upon the year of inception, amount of published manuscripts, and focus of specific interscholastic sport issues. The journals reviewed were the International Journal of Sport Management (IJSM), International Journal of Sport Marketing and Sponsorship (IJSMS), Journal of Amateur Sport (JAS), Journal of Applied Sport Management (JASM), Journal of Sport Economics (JSE), Journal of Sport Management (JSM), Sport Management Review (SMR), and Sport Marketing Quarterly (SMQ). These particular journals were selected because their websites indicated a focus/aim/mission/purpose on administration issues in sport.

Over a span of 30 years, with JSM being the oldest of these eight selected journals, only 22 articles have been published with a focus on interscholastic sport. To put this number in perspective, five of these journals are published quarterly, one journal is published three times per year, one journal is published five times annually, and one journal is published six times per year. Each journal on average consists of six articles per issue. Therefore, the total amount of articles printed among these eight sport management academic journals comes to 3,757 ; meaning only five-tenths of $1 \%$ of 
these journal articles focus on interscholastic sport issues. Approximately half of those articles were published during the last 5 years (12). Although it appears interscholastic sport is becoming more of an interest to academicians, none of the existing articles are comprehensive in their examination of contemporary issues effecting interscholastic sports.

Given the current gap of comprehensive studies on contemporary interscholastic athletic issues, the authors sought to address this void by identifying contemporary issues within interscholastic sport.

\section{Review of Literature}

The following review reflects administration issues identified by the Minnesota State High School League (MSHSL), whose members served as a panel of experts for this investigation. Administrators from this association were selected due to levels of experience, as well as proximity and personal connection to the first author. Demographic information for the members of the panel of experts is provided in the section Establishing a Panel of Experts. This panel of experts identified the ten most relevant issues surrounding interscholastic sport administration. These consisted of (1) risk minimization, (2) safety issues, (3) athletic training, (4) concussions, (5) health issues, (6) maintaining an educational focus, (7) travel teams, (8) athletic facilities, (9) transfer issues, and (10) online registration. The following review of literature provides a background of the existing literature in these areas.

\section{Risk Minimization and Safety Issues}

While students are ultimately in charge of their own safety, school personnel have similar responsibilities to parents regarding certain behaviors from students, as well as legal responsibilities for the safety and welfare of the children during school and extracurricular activities (Armenta, 2011). This is referred to as the common law concept called in loco parentis, a Latin term that is defined as "in place of parent" (Aquila, 2008, p. 104). Therefore, if student athletes are harmed in the engagement of school sports or other extracurricular athletic activities, the school is at risk of being responsible, which can result in legal action levied against the school (Armenta, 2011; Blackburn, Forsyth, Olson, \& Whitehead, 2013).

The fourteen duties of care owed by interscholastic programs were illustrated by Doleschal (2006). These include (1) duty to plan, (2) duty to supervise, (3) duty to assess athletes' physical readiness, (4) duty to maintain safe playing conditions, (5) duty to provide proper equipment, (6) duty to instruct properly, (7) duty to match athletes, (8) duty to provide proper physical conditioning, (9) duty to warn, (10) duty to provide injury insurance, (11) duty to develop an emergency response plan, (12) duty to provide proper emergency care, (13) duty to provide safe transportation, and (14) duty to select, train, and supervise coaches. 
A study conducted by Palmero, Dotterweich, Lhotsky, and Walker (2012) measured the implementation and enforcement of risk management plans designed to uphold these wide range of duties. Through a sample of athletic directors belonging to the National Interscholastic Athletic Administrators Association (NIAAA), $23.8 \%$ of high schools did not have a risk management plan (Palmero et al., 2012). Of the institutions that had a written plan, 28\% admitted that the risk management plan was not enforced (Palmero et al., 2012). In particular, only $46.9 \%$ of venues offered visible risk warning signs and $78.6 \%$ maintained automated external defibrillators (AEDs) (Palmero et al., 2012). Green (2015) reported that hundreds of legal cases are filed on an annual basis alleging failures to provide safeguards and protect the welfare of athletes.

Schools will often use assumption of risk as a legal defense for catastrophic injuries experienced by student athletes, however the assumption will not hold up in court if it is proven that the injured party was harmed due to "failure of teaching a proper technique, faulty or ill-fitting equipment, or other such causes that could have been alleviated by more prudent actions of coaches or other school personnel" (Aquila, 2008, p. 156). In order to avoid legal recourse, it is essential for coaches to instruct and teach the safest practice and in-game techniques to their participants through either verbal and model instruction or demonstration, as well as routinely in- spect protective equipment for any defects and making sure it correctly fits their participants (Aquila, 2008).

\section{Athletic Training}

In an attempt to reduce risk and increase safety for student athletes, schools will often hire an athletic trainer to their staff. According to the National Athletic Trainers' Association (2017), the services and practices by athletic trainers include " $\ldots$ injury and illness prevention, wellness promotion and education, emergent care, examination and clinical diagnosis, and therapeutic intervention and rehabilitation of injuries and medical conditions" (Para 3). A Delphi study implemented by Aldret (2018) sought to identify the perspectives of athletic trainers toward the necessary responsibilities and skills in their profession. The most common responses for tasks were "Understands return to play criteria vs. referral criteria" and "Uses proper techniques to minimize professional liability" (Aldret, 2018). Regarding skills, communication with coaches, parents, and athletes, as well as ability to act composed under pressure, were noted by all participants (Aldret, 2018). Having an athletic trainer on staff alleviates the pressure of coaches and athletic administrators to diagnose or make health care decisions for injured athletes, who are often not qualified in the medical field and could potentially put the student's life at risk (Dewitt, Unruh, \& Seshadri, 2012).

Despite the benefits that athletic trainers bring to the athletic adminis- 
tration staff, the majority of public and private schools do not have a full-time athletic trainer on staff (Pike, Pryor, Vandermark, Mazerolle, \& Casa, 2017). As of 2015, only $37 \%$ of public secondary schools had a full time athletic trainer on their staff (Pryor et al., 2015). Even more alarming is that as of 2017, only $28 \%$ of private secondary schools had a full time athletic trainer on staff (Pike et al., 2017). A qualitative study involving interscholastic administrators in West Virginia indicated their desire to employ full-time athletic trainers for all sports (Schneider, Meeteer, Nolan, \& Campbell, 2017). Within this theme, participants suggested the need for greater funding for the presence of athletic trainers (Schneider et al., 2017). While injury rates for student athletes are higher during competition than in practice, the volume of practice injuries warrant that it should not be ignored, further increasing the need for full-time athletic trainers (Rechel, Yard, \& Comstock, 2008). Some common barriers for entry found for most secondary schools for hiring athletic trainers were the lack of knowledge of the athletic trainer's role, school size, and budgetary constraints (Pike et al., 2017). A barrier to entry that was found to be unique for secondary public schools was rural locations (Pike et al., 2017).

Research conducted by McGuine et al. (2018) reflected a variety of statistically significant differences in terms of post-concussion management between high schools with low athletic trainer availability vs. high athletic trainer availability. Athletes in the low availability category waited an average of 24.0 hours until being consulted by an athletic trainer, as compared to 0.2 hours in high availability schools (McGuine et al., 2018). Athletic trainers at low availability schools contacted parents at a rate of $83.3 \%$, while parents were contacted $98.4 \%$ of the time by athletic trainers in high availability schools (McGuine et al., 2018). It was half as common (50\%) for low trainer availability schools to mandate return-to-play protocols than high availability programs (100\%) (McGuine et al., 2018). These substantial disparities support the need for full-time athletic trainers.

\section{Concussions}

According to DePadilla, Miller, Jones, Peterson, and Breiding (2018), approximately 2.5 million high school student-athletes (15.1\%) suffer concussions on an annual basis. In their study, 9.1\% of athletes reported one concussion, $3.0 \%$ indicated they received two concussions in the past 12 months, $1.0 \%$ were impacted by three concussions, and 2.0\% acknowledged four or more concussions (DePadilla et al., 2017). In emergency rooms there was a $62 \%$ increase in non-traumatic brain injuries for children under the age of 19 from 2001 to 2009 (CDC, 2009; Langlois, Rutland-Brown, \& Wald, 2006). The prevalence of concussions and non-traumatic brain injuries in adolescence can be attributed to adolescents having undeveloped necks and torsos, requiring less force to cause a 
concussion than older, developed athletes (Carman et al., 2015).

It is invaluable to have everyone involved with interscholastic athletics (e.g. athletic trainers, coaches, students, parents) understand the symptoms and health related risks of concussions. Large percentages of both male and female athletes are often found to not report their concussion because they do not believe them to be serious (Wallace, Covassim, \& Beidler, 2017). While the knowledge of concussions is similar in both male and female athletes, males are found to be 4-11 times less likely to report their concussion than their female counterparts, due to male athletes being aware of perceptions and reactions from others, which coincides with the male sports culture (Wallace et al., 2017).

Concussions also have a significant effect on a student athlete's secondary educational experience (Weber, Welch, \& Parsons, 2014; Williams, Welch, Parsons, \& Valovich, 2015). When considering interscholastic athletics are intended to help students learn outside of the classroom, a mission held around the country as "education-based athletics", it is of the utmost importance for athletic trainers to provide assistance and guidance to concussed student athletes to be able to perform in the classroom setting (Blackburn et al., 2013). Concussion signs and symptoms can be triggered by any activity that requires cognitive demand (e.g., reading, music, focusing on homework, paying attention in class) (Williams et al., 2015). It is often recommended practice that athletes who have incurred a sports-related concussion to pursue cognitive rest, which would include abstaining from academics until the injured athlete is symptom-free (Bey \& Ostick, 2009). However, even if concussed athletes start feeling better health wise, athletes who have suffered recent concussions performed significantly worse on measures of attention and concentration than athletes with no concussion history, making it important for them to take the prescribed required time off by trainers or physicians before they come back to the classroom (Moser, Schatz, \& Jordan, 2005).

Undoubtedly, concussion protocols have evolved at the high school level in recent years (Granitto \& Norton, 2018). These policies incorporate pre-participation counseling, assessment, diagnosis, and management (i.e., return to learn, return to play) (Granitto \& Norton, 2018). The authors supported the value of pre-participation counseling due to the observation that only $25 \%$ of parents reported a basic understanding of sport-related concussions (Granitto \& Norton, 2018). Post-concussion protocols include an individualized treatment plan involving return to play, serial patient monitoring, neuropsychological testing featuring the Sport Concussion Assessment Tool, and follow-up visits (Granitto \& Norton, 2018). Davies et al. (2018) conducted a qualitative study with 64 athletic trainers to evaluate concussion protocols. Results indicated that assessment or baseline tests, communication among involved 
parties, reliance on athletic trainer assessments, and return-to-learn policies are the four tenets of successful protocols (Davies et al., 2018). Athletic trainers responded that baseline tests involved Immediate Post-Concussion Assessment and Cognitive Testing (imPACT), immediate communication with parents is especially important, and that returnto-play requires a 48-hour symptom-free period (Davies et al, 2018).

\section{Health Issues}

Interscholastic sport is often associated with healthy behavior and benefits for student athletes, such as proper nutrition habits, positive psychological attitudes, health practices, and academic achievement (CDC, 2017a; CDC, 2017b; Lipowski \& Bielenink, 2014). Participation in physical activity additionally can lead to higher goal-oriented behavior, which can enforce less risky behavior for student athletes (Jochimek, Krokosz, \& Lipowski, 2017). However, studies and reports of risky behavior amongst youth athletes is quite varied (Diehl et al., 2012). The following section reports existing literature related to the effects of sport participation on these health-related topics: alcohol use, tobacco use, illicit drug use, steroid abuse, performance-enhancing substances, and violence.

In a systematic literature review completed by Diehl et al. (2012) surrounding alcohol consumption, tobacco use, and illicit drug abuse, studies tend to report less smoking and recreational drug use by student athletes, yet higher alcohol and smokeless tobacco use. For example, Taliaferro, Rienzo, and Donovan (2010) observed that marijuana use was significantly lower among high school athletes than their non-athlete peers. On the other hand, the odds ratio for elite adolescent student-athletes to drink alcohol was higher than non-athletes (Peretti-Watel et al. 2003), and the odds ratio for tobacco use was 33\% higher for athletes than those not participating in organized sport (Castrucci, Gerlach, Kaufman, \& Orleans, 2004). The higher consumption of alcohol and smokeless tobacco should be a cause for intervention from high school athletic administration (Diehl et al., 2012).

The pressure to perform at a high level in interscholastic sport can also generate health issues in adolescent student athletes. In a longitudinal study, 1.7\% of male and $1.4 \%$ of female adolescent athletes admitted to steroid use for the purpose of gaining muscle (van den Berg, Neumark-Sztainer, Capri, \& Wall, 2007). Students who disclosed using legal performance enhancing substances reported higher levels of involvement in physical activity, which includes athletic competition (Bell, Dorsch, McCreary, \& Hovey, 2004). Among a sample of adolescent athletes, $8.0 \%$ had taken a legal performance-enhancing drug, while $1.6 \%$ reported use of anabolic steroids (AS) (Dodge \& Jaccard, 2006). There was a relationship among these behaviors, as athletes who consumed legal performance-enhancing drugs were 26 times more likely to also use anabolic steroids 
(Dodge \& Jaccard, 2006). While permissible dietary substances are legal to purchase and consume, they should be taken with caution. As Dodge and Jaccard (2006) stated:

...there is an abundance of legal dietary supplements available that claim to improve athletic/physical performance. Some of the supplements available replenish nutrients lost during exercise and are relatively safe (e.g., creatine), whereas others mimic the effects of AS (e.g., Dehydroepiandrosterone) and may have side effects similar to those associated with AS use. (p. 367)

The cause for the consumption of these dietary supplements is often considered to be an erroneous perception from athletes that they can be used to better their athletic performance (Bell et al., 2004). In this instance, it is important for those involved with high school sport to highlight the facts and side effects of legal performance enhancing supplements for student athletes and push for their prevention in an athletic setting (Dodge \& Jaccard, 2006).

Lastly, sport participation (especially in contact sports) has been positively related to a susceptibility for violence. Kreager (2007) observed that adolescent wrestlers were $45 \%$ more likely than non-athletes to become involved in physical fights, while football players displayed a $40 \%$ more likelihood than non-athletes to resort to physical violence. Based on these results, it appears that alcohol and tobacco use, anabolic steroid abuse, consumption of performance-enhancing drugs, and violence are risks of sport participation.

\section{Educational Focus}

The range of administration duties for high school athletic departments also includes that their high school maintains an educational focus. Interscholastic athletics are considered to be the other half of education, as education-based athletics are in place to provide students with a learning experience that is outside of the classroom (Gardner, 2015). Research suggests that competing in sport can increase cognitive ability and enhance academic performance in athletes, as physical activity increases blood flow to the brain, which enhances mood, mental alertness, and improves self-esteem (Bailey, 2006; Hills, 1998).

Yet in recent years, there is an apparent overemphasis by stakeholders being put on winning as the most important measure of success in interscholastic athletics, not the development of student athletes (Johnson, Giannoulakis, \& Scott, 2017). In their semi-structured interviews of high school athletic administrators across six states, a common theme was that the culture of winning permeates the culture of interscholastic athletics (Johnson et al., 2017). Gard (2017) highlighted the decline in academic expectations of student-athletes. Only 31 of $50(62 \%)$ of states in the United States required course completion requirements for athletic eligibility (Gard, 2017). Furthermore, from 1995 to 2014, the per- 
centage of states requiring student-athletes to complete a minimum of four core courses decreased from $27(54 \%)$ to 26 (52\%) Gard (2017). Considering that the National Collegiate Athletic Association has raised minimum academic requirements over the same time period, Gard (2017) warned that high school programs have not upheld their educational focus.

It is important for athletic administrators to keep their focus on the true goal of interscholastic athletics. As Gardner and Van Erk (2011) stated, "Success at the high school level has more to do with preparing students for their lives after sports than the number of victories or state championships" (p. 1). Despite this ideal, Meier et al. (2004) found that unit increases in athletic budgets predicted approximately a 45 -point decrease in student SAT scores and 1.2 points on the ACT exam. The culmination of these results indicates inconsistencies between the mission of academics and athletics.

\section{Travel Teams}

Travel teams can also pose a unique issue for U.S. high school athletic administration. Contrary to the United States, countries around the world usually require adolescents who want to participate in competitive athletics to join club or teams located in their cities, as academics and athletics are detached from one another (Johnson, Lower, Scott, \& Manwell, 2018). Interscholastic athletics is widely held perspective within the United States that athletics should be included with the traditional academic experience (Hums \& MacLean, 2013; Hyland, 2008). Student athletes have prioritized their club teams over their high school teams, causing some state association governing bodies to implement policies prohibiting athletes from playing on travel club teams in the same season they play the sport in high school (Pennington, 2003). High school coaches around the country often posit that travel teams focus too much time on competition and winning, rather than working on the fundamentals of the sport (Coach \& AD, 2010).

Despite the proliferation of club and travel teams in the United States, there has been a limited amount of research in this area. Willis (2016) illuminated the perspective of former Amateur Athletic Union (AAU) participants toward their experiences in terms of academic requirements, time and money, basketball development, and opportunity to compete at the college level. Among the study's results, $42 \%$ of subjects disagreed that AAU athletes must succeed academically, and more disagreed (42\%) than agreed $(30 \%)$ that AAU enhances their ability to become a better teammate (Willis, 2016). Not only can club and travel teams harm interscholastic athletics, but they can also distract from the mission of sport.

\section{Athletic Facilities}

Athletic administrators are also in charge of scheduling the use of their athletic facilities and their routine maintenance for both their athletic teams 
throughout the season and for community events held at their facilities (Blackburn et al., 2013). Challenges usually arise from schools having to use off-site or unowned facilities to hold practices or games, making it of the utmost importance by administrators to schedule far in advanced potential practice and game schedules to ensure that they can fit them in the rented facilities' schedule (Chorosiewski \& Whitten, 2009). Assessments and maintenance of athletic facilities needs to be an ongoing process to ensure the safety of both the student-athletes and spectators attending their games (Armenta, 2011).

\section{Transfer Issues}

Across the nation, high schools are often dealing with students transferring in and out of their schools. All students that transfer from one school to another are tracked by state athletic associations, and while most transfers are dealt with in an easy fashion, there is an exclusive predicament associated for students who compete in interscholastic athletics and have a high athletic reputation (Johnson et al., 2018). Each state has its own competitive balance policies measures in place created by state athletic associations, in which some have rules which specifically state transfers deemed "athletically-motivated" to be illegal, which is to defer other schools from recruiting athletes, subsequently "stacking" their teams (Johnson et al., 2018). Transfer restrictions are almost always found constitutional and do not violate student's'
First or Fourteenth Amendment rights, in which courts side with state athletic associations to restrict a transfer.

In the event that a case favors a student, it often occurs in cases where “... an administrator error occurred in the waiver process... the transfer rule conflicted with state educational law... the transfer was due to educational reasons... or the students did not meet academic requirements at a private school" (Johnson et al., 2018, p. 12). The fact that cases have been decided to both favor the state athletic associations as well as the student has caused some outrage from stakeholders, often due to misconceptions that transfer restrictions are random and not uniform. There are also no rules that penalize or restrict students from transferring schools for academic or other extra-curricular motivations, creating a sense of double standard against athletes, which magnifies stakeholder indignation (Windsor, 2018). Athletic administrators should take time to educate themselves and other stakeholders within interscholastic sports on state athletic association policies, in order to abate future sanctions (Johnson et al., 2018).

\section{Online Registration}

Finally, athletic administrators are tasked with keeping up to date with electronic filing software and programs is also administratively important for athletic departments. Student-athletes are often required to report personal information such as their medical exam and physical exam information and 
emergency contact information by high school athletic departments (Blackburn et al., 2013). The use of electronic filing software enables athletic departments to scan and file these documents in order to be easily accessible. The information is there to ensure best practice for coaches to care for their athletes or in the case of an emergency situation.

\section{Purpose}

The literature reviewed for this research study offers an overview of salient administration issues that pertain to interscholastic sport. However, the literature does not provide insight to how important these issues are to athletic administrators that oversee their respective high school athletic programs. To address this gap, the current study identifies how important contemporary administration issues are to practicing interscholastic athletic administrators today, as well as for the next five years. By addressing the importance level of these issues, this study would support and compliment the current body of literature on interscholastic sport. Additionally, this study provides a benchmark for decisions in interscholastic athletic policies and guidelines for the betterment of all high schools, administrators, coaches, officials, parents, and student-athletes.

Two previous studies served as a model for the current investigation; Branch and Crow's (1994) Intercollegiate Athletics: Back to the Future? and Drain and Ashley's (2000) Back to the Future II: A Comparison with Branch and Crow
Five Years Later. These studies identified contemporary issues surrounding collegiate sports, serving to potentially inform intercollegiate athletic policy. The current investigation has pursued the same purpose regarding administrative issues within interscholastic athletics. Thus, three questions guided this research study: a) What are the administration issues most pertinent to interscholastic sport today, as well as in the future? b) How important are those administration issues to athletic administrators?, and c) What are the potential implications of those pertinent administration issues to practicing athletic administrators?

\section{Methodology}

This mixed-methods non-experimental descriptive study was driven on the reliance of well-rounded, renowned athletic administrators. Although state differences in law and regulations can vary, those who are employed within interscholastic sports encounter the same baseline issues within their profession on a day-to-day basis. Case in point: the $\mathrm{Na}$ tional Interscholastic Athletic Administrators Association (NIAAA) professional certification program currently consists of 47 leadership training courses ranging from finance, marketing, facilities, equipment, sports medicine, personnel, law, and a host of many other issues that fall under the responsibility of the athletic administrator. These leadership training courses have been designed to help both incoming and seasoned athletic administrators to better handle issues encoun- 
tered regularly. It was pertinent to this study that those chosen to participate in this study had the most training available. The methodology for this research study consists of the following four phases: 1) establishing a panel of experts, 2) identifying and defining contemporary issues, 3) survey development and distribution, 4) data analysis and interviews. Out of convenience, the Minnesota State High School League (MSHSL) was approached to begin this investigation.

\section{Establishing a Panel of Experts}

The MSHSL executive director was contacted by phone. After discussing a possible research study that would eventually make its way to the NIAAA annual conference, the MSHSL executive director agreed to have his executive board, 20 high school administrators well accustomed to contemporary issues surrounding athletic programs, serve as a panel of experts. The 20 members of the MSHSL executive board represent the following: a) athletic administrators, b) coaches, c) principals, d), superintendents, e) Minnesota school board association members, f) Minnesota association of secondary schools administrators, $g$ ) middle school \& high school sports coordinators, h) interscholastic activities administrators, i) all district coordinators across Minnesota, and j) the general public across Minnesota. In other words, all 20 board members have an invested interested in high school athletics; thereby, creating a well-rounded holistic membership repre- senting interscholastic sports throughout the state of Minnesota.

\section{Identifying and Defining Contemporary Issues}

During the next scheduled MSHSL board meeting, the executive director shared the purpose of the study with his executive board. Each executive board member was instructed to identify five contemporary issues pertinent to interscholastic sports today, as well as the next five years. The executive director collected responses from each of his board members, and forwarded them to the authors.

When the authors received the issues by mail, some of the issues were not fully defined, only offering descriptive words. Therefore, the MSHSL executive director worked with his board members to properly define all contemporary issues as they relate to the day-to-day operations of practicing athletic administrators. Once all contemporary issues were properly defined, the MSHSL executive director forwarded all definitions to the authors electronically.

\section{Survey Development and Distribution}

The MSHSL submitted a total of 100 issues; however, 30 of those issues did overlap. Therefore, the panel of experts identified a total of 70 contemporary issues, which were labeled under one of 14 categories: Administration, Classification, Coaches, Ethics, Finance, Officials, Parents, Participation, Schedul- 
ing, Specialization, Sportsmanship, Title IX, Tournaments, and Other. These 14 categories, along with 70 pertinent issues were merged with a Likert scale with values ranging from 5 (extremely important) to 1 (very little importance). ${ }^{1}$ The 14 categories were created after reviewing the all issues submitted by the panel of experts. In other words, the issues themselves were the driver in establishing and naming the categories.

For example, when several issues came forward involving 'Parents' those issues would be placed under a category titled 'Parent Issues.' When several issues came forward involving 'Participation' those issues would be placed under a category titled 'Participation Issues.' Therefore, of the 10 issues eventually placed under the 'Administration Issues' category, these issues were considered having an administration mandate set down and enforced by powers to be that makes such administration decisions.

The North Dakota Interscholastic Athletic Administrators Association (NDIAAA) was selected to serve as the pilot study out of convenience due to proximity of the primary author. The NDIAAA executive secretary was contacted by phone requesting to have the survey completed during their state conference. In consultation with the acting president, the association agreed to assist with this pilot study. The NDIAAA agreed to have the survey completed during their spring conference

${ }^{1}$ This manuscript only focuses on 10 pertinent issues labeled under the Administration category. business meeting to help ensure a good response rate. The primary investigator did attend the NDIAAA state conference and presented copies of the survey during the pre-business meeting. Before respondents completed the survey, the lead author explained the intent of the research study, as well as welcoming any comments respondents deemed necessary. The participants $(\mathrm{N}=56)$ then completed the survey. The respondents to the pilot study were all practicing athletic administrators throughout the state of North Dakota who elected to attend the NDIAAA annual conference held in Fargo, North Dakota. These participants were beginning to well-seasoned athletic administrators representing their respective schools and districts. The primary author also had the opportunity to welcome suggestions to help improve the survey's clarity and purpose before approaching the NIAAA. No suggestions were presented.

The NIAAA executive director was contacted by phone by asking permission to have the survey completed during the association's annual national conference. After further discussion the NIAAA executive director agreed and selected to have the survey completed during the scheduled section- 8 district business meetings. Each of the section- 8 districts consists of athletic administrators representing their respective state:

$$
\begin{aligned}
& \text { Section } 1 \text { - CT, DE, ME, MA, NH, } \\
& \quad \text { NJ, NY, RI, VT } \\
& \text { Section } 2 \text { - KY, MD, OH, PA, VA, WV }
\end{aligned}
$$


Section 3 - AL, FL, GA, LA, MS, NC, SC, TN

Section 4 - IL, IA, IN, MI, WI

Section 5 - KS, MN, MO, NE, ND, SD

Section 6 - AR, CO, NM, OK, TX

Section 7 - AZ, CA, HI, NV, UT

Section 8 - AK, ID, MT, OR, WA, WY

The section- 8 business meetings were suggested to help ensure a national perspective was achieved. This resulted in a cluster sample by section. The survey instrument was sent electronically to the NIAAA executive director, which was then distributed to each of the business meeting leaders. Each section-8 leader was presented a sufficient number of surveys, and in turn each leader distributed the survey to those who attended their respective section- 8 business meeting. All completed surveys were labeled by section and returned to the executive director $(N=170)$. The respondents of the national study were all practicing athletic administrators throughout the country representing their respective region. Individuals serving as a regional representative during the NIAAA annual conference are typically experienced athletic administrators that have a full grasp of today's contemporary issues surrounding interscholastic sport. Their service as a regional representative is up to four years, serving as the gate-keeper of their respective state membership and the national membership. The executive director then mailed all completed surveys by section to the primary author. The authors were informed a total of
447 athletic administrators attended their respective section meeting; thereby, a $38 \%$ response rate was achieved.

Multiple procedures were put into place to ensure reliability and validity for the quantitative component of the study. The MSHSL served as the panel of experts to establish face validity (Andrew, Pedersen, \& McEvoy, 2011). After the authors identified 70 potential issues, placed them into 14 categories, and created a three-level 5-point Likert-scale to rate each issue, the survey was sent back to the MSHSL for review. The board members expressed confidence that the survey represented the contemporary issues in interscholastic athletics, thus no changes were made. Reliability was generated through a pilot study (Andrew et al., 2011), which consisted of attendees at the North Dakota Interscholastic Athletic Administrators Association (NDIAAA) meeting. Participants in the pilot study responded that the survey was concise and understandable, so the existing survey was completed with the sample population.

A thorough process was also followed for the qualitative aspect. Following the survey, four athletic administrators were contacted for follow-up semi-structured interviews. Each interviewee agreed to respond to each of the four administration issues that were deemed "very important" through the survey. Interviewees were conducted via e-mail due to logistical challenges. Responses were developed into codes and themes based on 
the verbatim responses. Member checks were collected, and each interviewee validated their responses.

\section{Data Analysis and Interviews}

These 170 surveys provided a total of 11,900 data points. Using SPSS statistical software program the following descriptors were computed; number, range, minimum, maximum, mean, and standard deviation. To determine whether a significant difference existed among the administration issues across sections, a one-tail analysis of variance (ANOVA) was conducted, set at an alpha level of .05 . The analyses indicated several contemporary issues were found to be significant. Therefore, a Games-Howell posthoc test was then computed to determine significant differences across geographic sections. The justification behind selecting the Games-Howell post-hoc test was two-fold: a) this particular post-hoc uses a nonparametric approach in comparing groups and regional sections, and b) the Games-Howell post-hoc test is the most appropriate when variances and sample sizes are not equal (Maxwell and Delaney, 1991). As sample sizes varied across regional sections, the Games-Howell posthoc test was most suitable.

After completing the data analysis, the data revealed particular areas athletic administrators might focus their attention. Four semi-structured interviews from four different interscholastic athletic administrators were then conducted to gain a deeper understanding of these con- temporary administration issues, which included the executive director of an interscholastic athletic association (personal communication, February 2, 2017), executive secretary of a state high school athletic association (personal communication, January 27, 2017), executive director of a state interscholastic association (personal communication, August 18, 2016) and president of a regional athletic administration board (personal communication, July 18, 2016). These four interscholastic athletic administrators have a combined experience of more than 100 years of knowledge as practicing athletic administrators.

\section{Results}

The following sections are discussed in response to the results of this interscholastic sport research study: 1) definition of terms, 2) expanding variances for level of importance, 3) comparison of pilot and national descriptive results, and 4) sectional differences by issues.

\section{Definition of Terms}

The contemporary administration issues were presented and properly defined by the MSHSL executive board members specific for this investigation. An appendix is provided for the reader to review the contemporary administration issues that are pertinent today, as well as the next five years. 


\section{Appendix: Definition of Terms}

Administration Issues

1. Athletic Facilities. Venues where athletic practices and contests are conducted.

2. Athletic Training. Addressing the physical needs of student athletes.

3. Concussions. Severe blow to the head causing bruising of the brain.

4. Health Issues. Anything that might adversely affect the health of students.

5. Maintaining Educational Focus: Understanding the role athletics plays in the overall development of students.

6. Online Registration: Electronic filing of required paperwork for any activity.

7. Risk Minimization: Implementing best practices to ensure athletic practices and contests are as safe as possible.

8. Safety Issues: Anything that impacts the ability to provide a safe environment.

9. Transfer Issues: Students moving from one school to another for many different reasons.

10. Travel Teams: Non-school teams.

Expanding Variances for Level of Importance

Athletic administrators rated all administration issues according to level of importance $(5=$ very important, $1=$ of least importance). Once the data was calculated the authors interpreted athletic administrator's importance level through the lens of additional variances when ranking mean scores. Therefore, Table 1 shares the expanded variances regarding athletic administrators' level of importance on administration issues.

\section{Pilot Study and National Results}

The NDIAAA served as the pilot study to test the level of importance for each of the 10 administrative issues, as well as the NIAAA serving as the national sample. Table 2 shares the descriptive comparison of both the pilot and national sample results.
Administration Issues. The descriptive results from the pilot studies conducted with the NDIAAA indicated that Concussions, Maintaining Educational Focus, and Risk Minimization, and Safety Issues (tied for third) as its four highest rated issues in order. Results from the national sample were closely correlated with the pilot sample, which found Concussions, Risk Minimization and Safety Issues (tied for second), and Maintaining Educational Focus as its four most important issues, in order. Although the second and third issues from both results were switched, the inclusion of both with each result supported each other.

Sectional Differences. The NIAAA executive director's suggestion to have surveys completed during the section- 8 business meetings, presented the authors the opportunity to review of data results across sections (e.g., regions of the coun- 
Table 1

Athletic Administrators Level of Importance on Administrative Issues

\begin{tabular}{ll}
\hline Survey Rating Scale & Expanded Rating Lens \\
\hline $5=$ extremely important & $5.0-4.5=$ extremely high importance \\
$4=$ very important & $4.4-4.0=$ very high importance \\
& $3.9-3.5=$ high importance \\
& $3.4-3.0=$ important \\
$3=$ important & $2.9-2.5=$ somewhat important \\
$2=$ somewhat important & $2.4-2.0=$ low importance \\
& $1.9-1.5=$ very low importance \\
$1=$ very little importance & $1.4-1.0=$ extremely low importance \\
\end{tabular}

Table 2

Administration Issues for National and Pilot Samples

\begin{tabular}{lllll}
\hline \multirow{2}{*}{ Issue } & \multicolumn{3}{c}{ National Sample } & \multicolumn{2}{c}{ Pilot Sample } \\
& $\mathrm{X}$ & $\mathrm{SD}$ & $\mathrm{X}$ & $\mathrm{SD}$ \\
\hline Athletic Facilities & 3.80 & .956 & 3.66 & .725 \\
Athletic Training & 3.74 & 1.02 & 3.57 & .938 \\
Concussions & $4.40^{1}$ & .855 & $4.50^{1}$ & .716 \\
Health Issues & 3.46 & 1.08 & 3.63 & .952 \\
Maintaining Ed Focus & $4.04^{3}$ & .955 & $4.20^{2}$ & .939 \\
Online Registration & 3.11 & 1.02 & 2.38 & 1.02 \\
Risk Minimization & $4.12^{2}$ & .919 & $4.16^{3}$ & .764 \\
Safety Issues & $4.12^{2}$ & .926 & $4.16^{3}$ & .811 \\
Transfer Issues & 3.69 & .962 & 3.05 & .911 \\
Travel Teams & 3.07 & 1.07 & 2.75 & 1.10 \\
\hline
\end{tabular}

\footnotetext{
${ }^{1}$ Rated most important; ${ }^{2}$ Rated second most important; ${ }^{3}$ Rated third most important.
} 
try). The one-tail ANOVA did reveal significance among four administrative issues: Athletic Facilities, Athletic Training, Health Issues, and Travel Teams (see Table 3).

Sectional differences were found to be significant for Athletic Facilities $\mathrm{F}(7,158)=2.776, \mathrm{p}=.009 ;$ Athletic Training $\mathrm{F}(7,159)=4.513, \mathrm{p}<.000 ;$ Health Issues $\mathrm{F}(7,158)=4.302, \mathrm{p}<.000 ;$ and Travel Teams $\mathrm{F}(7,156)=3.740, \mathrm{p}=.001$.

Once computed, the Games-Howell post-hoc test did indicate significance across sections for these four administration issues. Table 4 presents the crosstabs indicating where sectional significant differences occurred.

Significant differences that occurred across sections (e.g., regions of the country) extended beyond the original scope of this investigation. For instance, Athletic Facilities was rated higher in section 6 than sections 1-5 and 7-8. Therefore, athletic administrators in the Lower Midwest region of the country (Arkansas, Colorado, New Mexico, Oklahoma, and Texas) rated Athletic Facilities higher than athletic administrators in other regions of the country, and that difference was significant. The remaining issues can also be viewed and evaluated in this same regard. Although these sectional differences are interesting, the purpose of this study does not intend to explain why these sectional differences exist. Therefore, the authors of this investigation are unable to elaborate any further on these sectional differences. However, the authors will suggest further research on these sectional differences later.

\section{Discussion}

The first two propositions have been addressed. First, administration issues have been identified that are pertinent to interscholastic sport today, as well as the next five years. Second, athletic administrators rated how important those administration issues are within the day-to-day operation of their athletic programs. The third proposition will now be addressed: What are the potential implications of those pertinent administration issues to practicing athletic administrators?

To complete this mixed-methods non-experimental descriptive study, semi-structured interviews were conducted to provide insight on the potential implications of the contemporary administration issues. Quantitative data alone does not provide the breadth and depth needed to understand why these issues are important to athletic administrators. Therefore, in an attempt to connect the review of literature and the findings of this investigation, Denzin and Lincoln (2018) suggest interviews have the ability to bring insight that analysis of quantitative data alone does not provide.

\section{Administration Issues}

All ten administration issues identified in this study were rated important to athletic administrators across the country. Four of those issues were rated as 
Table 3

National Sample: Administration Issues by Section

\begin{tabular}{|c|c|c|c|c|c|c|c|c|c|}
\hline & Nat'l & $\mathrm{S} 1$ & S2 & S3 & S4 & S5 & S6 & S7 & S8 \\
\hline \multicolumn{10}{|l|}{ Athletic Facilities * } \\
\hline $\mathrm{N}$ & 166 & 8 & 24 & 16 & 13 & 21 & 22 & 37 & 25 \\
\hline $\mathrm{X}$ & 3.80 & 3.63 & 3.88 & 4.13 & 3.31 & 3.52 & 4.41 & 3.59 & 3.80 \\
\hline SD & .956 & .744 & .899 & .957 & .854 & .872 & .908 & .864 & 1.11 \\
\hline \multicolumn{10}{|l|}{ Athletic Training * } \\
\hline $\mathrm{N}$ & 167 & 8 & 25 & 17 & 13 & 20 & 22 & 37 & 25 \\
\hline $\mathrm{X}$ & 3.74 & 3.25 & 3.72 & 4.35 & 3.31 & 3.15 & 4.41 & 3.57 & 3.84 \\
\hline SD & 1.02 & .707 & 1.06 & .785 & 1.18 & 1.03 & .734 & .929 & 1.02 \\
\hline \multicolumn{10}{|l|}{ Concussions } \\
\hline $\mathrm{N}$ & 168 & 8 & 25 & 17 & 13 & 21 & 22 & 37 & 25 \\
\hline $\mathrm{X}$ & 4.40 & 4.75 & 4.52 & 4.53 & 4.15 & 4.33 & 4.59 & 4.05 & 4.60 \\
\hline SD & .855 & .462 & .822 & .799 & .987 & 1.06 & .796 & .941 & .500 \\
\hline \multicolumn{10}{|l|}{ Educational Focus } \\
\hline $\mathrm{N}$ & 163 & 8 & 23 & 17 & 13 & 20 & 20 & 37 & 25 \\
\hline $\mathrm{X}$ & 4.04 & 4.13 & 4.04 & 4.35 & 4.31 & 3.65 & 4.25 & 3.95 & 3.92 \\
\hline $\mathrm{SD}$ & .955 & .991 & .975 & .785 & .630 & .988 & .910 & .970 & 1.11 \\
\hline \multicolumn{10}{|l|}{ Health Issues $*$} \\
\hline $\mathrm{N}$ & 166 & 8 & 24 & 17 & 13 & 20 & 22 & 37 & 25 \\
\hline $\mathrm{X}$ & 3.46 & 4.00 & 3.71 & 4.00 & 3.46 & 2.70 & 3.95 & 3.30 & 3.08 \\
\hline SD & 1.08 & 1.06 & .954 & .866 & .877 & 1.03 & 1.17 & .845 & 1.18 \\
\hline \multicolumn{10}{|l|}{ Online Registration } \\
\hline $\mathrm{N}$ & 163 & 8 & 25 & 17 & 13 & 20 & 21 & 37 & 25 \\
\hline $\mathrm{X}$ & 3.11 & 2.38 & 3.40 & 3.24 & 3.00 & 3.05 & 3.24 & 3.05 & 3.05 \\
\hline SD & 1.02 & .916 & 1.15 & .903 & 1.15 & 1.05 & .995 & .911 & 1.09 \\
\hline \multicolumn{10}{|l|}{ Risk Minimization } \\
\hline $\mathrm{N}$ & 166 & 8 & 25 & 16 & 13 & 20 & 22 & 37 & 25 \\
\hline $\mathrm{X}$ & 4.12 & 4.25 & 4.04 & 4.19 & 3.69 & 3.85 & 4.41 & 4.08 & 4.36 \\
\hline $\mathrm{SD}$ & .919 & .886 & .888 & .910 & 1.10 & 1.03 & .667 & .893 & .952 \\
\hline \multicolumn{10}{|l|}{ Safety Issues } \\
\hline $\mathrm{N}$ & 165 & 8 & 25 & 17 & 13 & 21 & 21 & 36 & 25 \\
\hline $\mathrm{X}$ & 4.12 & 4.13 & 4.36 & 4.35 & 3.85 & 3.86 & 4.38 & 3.89 & 4.17 \\
\hline SD & .926 & .834 & .757 & .861 & 1.28 & .963 & .804 & .949 & .916 \\
\hline \multicolumn{10}{|l|}{ Transfer Issues } \\
\hline $\mathrm{N}$ & 167 & 8 & 25 & 17 & 12 & 21 & 22 & 37 & 25 \\
\hline $\mathrm{X}$ & 3.69 & 3.75 & 3.96 & 4.00 & 3.83 & 3.29 & 3.68 & 3.81 & 3.28 \\
\hline SD & .962 & .707 & .978 & .790 & .937 & .902 & .994 & .938 & 1.06 \\
\hline \multicolumn{10}{|l|}{ Travel Teams * } \\
\hline $\mathrm{N}$ & 164 & 8 & 24 & 17 & 13 & 20 & 21 & 36 & 25 \\
\hline$X$ & 3.07 & 2.63 & 3.67 & 3.65 & 3.46 & 2.55 & 3.10 & 2.86 & 2.76 \\
\hline SD & 1.07 & 1.18 & .963 & .996 & .967 & 1.05 & 1.09 & .798 & 1.23 \\
\hline
\end{tabular}

* Denotes sectional significant difference existed. 
Table 4

Crosstabs for Administrative Issues by Section

Athletic Facilities

\begin{tabular}{lcccccccc}
\hline & S1 & S2 & S3 & S4 & S5 & S6 & S7 & S8 \\
S1 & & -.25 & -.50 & .32 & .10 & $-.78^{*}$ & .03 & -.17 \\
S2 & .25 & & -.25 & .57 & .35 & -.53 & .28 & .07 \\
S3 & .50 & .25 & & $.82^{*} .60$ & -.28 & .53 & .32 \\
S4 & -.31 & -.57 & $-.82^{*}$ & & -.22 & $-1.1^{*}$ & -.27 & -.49 \\
S5 & -.01 & -.35 & -.60 & .22 & & $-.88^{*}$ & -.07 & -.28 \\
S6 & $.78^{*}$ & .53 & .28 & $1.1 *$ & $.88^{*}$ & & $.81^{*} .61 *$ \\
S7 & -.03 & -.28 & -.53 & .29 & .07 & $-.81^{*}$ & -.20 \\
S8 & .17 & -.07 & -.32 & .49 & .28 & $-.61 *$ & .20 \\
\hline
\end{tabular}

Health Issues

\begin{tabular}{lcccccccc}
\hline & S1 & S2 & S3 & S4 & S5 & S6 & S7 & S8 \\
S1 & & .29 & .00 & .54 & $1.3^{*}$ & .04 & .70 & $.92^{*}$ \\
S2 & -.29 & & -.29 & .24 & $1.0^{*}$ & -.25 & .41 & $.63^{*}$ \\
S3 & .00 & .29 & & .54 & $1.3^{*}$ & .04 & $.70^{*}$ & $.92^{*}$ \\
S4 & -.54 & -.25 & -.54 & & $.76^{*}$ & -.49 & .16 & .38 \\
S5 & $-1.3 *-1.0^{*}$ & $-1.3^{*}$ & $-.76^{*}$ & & $-1.2^{*}$ & $-.60^{*}$ & -.38 \\
S6 & -.04 & .25 & -.04 & .49 & $1.2^{*}$ & & $.66^{*}$ & $.87^{*}$ \\
S7 & -.70 & -.41 & $-.70^{*}$ & -.16 & $.60^{*}$ & $-.66^{*}$ & & .22 \\
S8 & $-.92^{*}-.63^{*}-.92^{*}$ & -.38 & .38 & $-.87^{*}$ & -.22 &
\end{tabular}

* Denotes sectional differences.

very high importance; Concussions, Risk Minimization, Safety Issues, and Maintaining Educational Focus. These four highest rated administration issues will be at the forefront of the discussion.

Concussions. As stated earlier, one of the largest concerns among shareholders within interscholastic sports is the issue of concussions among student-athletes (Carman et al., 2015; CDC, 2009; Langlois et al., 2006). Athletic
Athletic Training

\begin{tabular}{|c|c|c|c|c|c|c|c|c|}
\hline & S1 & S2 & S3 & S4 & S5 & S6 & S7 & S8 \\
\hline S1 & & -.47 & $-1.1 *$ & -.05 & .10 & $-1.2^{*}$ & .31 & -.59 \\
\hline S2 & .47 & & $-.63^{*}$ & .41 & $.57 *$ & ${ }^{k}-.69 *$ & <.15 & -.12 \\
\hline S3 & $1.1^{*}$ & k.63* & & $1.0^{*}$ & $1.2^{*}$ & -.06 & $.78^{*}$ & * . .51 \\
\hline S4 & .06 & -.41 & $-1.0^{*}$ & & .16 & $-1.1^{*}$ & $k-.26$ & -.53 \\
\hline S5 & -.10 & $-.57 *$ & $-1.2 *$ & .16 & & $-1.3^{*}$ & -.42 & $-.69 *$ \\
\hline S6 & $1.2 *$ & k .69* & .06 & $1.1^{*}$ & $1.2^{*}$ & & & $* .57 *$ \\
\hline S7 & .32 & -.15 & $-.78^{*}$ & .26 & .42 & $-.84^{*}$ & & -.27 \\
\hline S8 & .59 & .12 & -.51 & .53 & $.69 *$ & $-.57^{*}$ & .27 & \\
\hline
\end{tabular}

\section{Travel Teams}

\begin{tabular}{|c|c|c|c|c|c|c|}
\hline & S1 S2 & S3 S4 & S5 & S6 & S7 & S8 \\
\hline S1 & $-1.0^{*}$ & ${ }^{*}-1.0 *-.83$ & .08 & -.47 & -.24 & -.13 \\
\hline S2 & $1.0^{*}$ & . $02 \quad .20$ & $1.1^{*}$ & .57 & $.81 *$ & $.91 *$ \\
\hline S3 & $1.0^{*}-.02$ & .18 & $1.1^{*}$ & .55 & $.79 *$ & $.89 *$ \\
\hline S4 & $.84-.20$ & -.18 & $.91 *$ & .37 & .60 & $.70^{*}$ \\
\hline S5 & $-.07-1.1^{*}$ & $-1.1^{*}-.91 *$ & & -.54 & -.31 & -.21 \\
\hline S6 & $.47-.57$ & $\begin{array}{lll}-.55 & -.37\end{array}$ & .54 & & .23 & .33 \\
\hline S7 & $.24-.81 *$ & $-.79 *-.60$ & .31 & -.23 & & .10 \\
\hline S8 & $.13-.91 *$ & $-.89 *-.70 *$ & .21 & -.33 & -.10 & \\
\hline
\end{tabular}

administrators have the daunting task to ensure all shareholders of interscholastic sports become aware of the symptoms when student-athletes are experiencing a potential concussion, as student-athletes often fail to report their concussion symptoms. One avenue athletic administrators could take is to ensure a certified athletic trainer is employed and on-hand during practices and competitions (Wallace et al., 2017; Weber, Welch, \& Par- 
sons, 2014; Williams, Welch, Parsons, \& Valovich, 2015).

The findings of the current study is in agreement with the literature, in that the prime concern of athletic administrators among all administration issues considered in this study is concussions. An upper-level administrator in a state athletic association has stated, "Concussion management is certainly one of the "hot button" topics in interscholastic sports today." Another member of a national interscholastic association goes on to say:

Concussion management and return to play protocols are clearly a huge concern among athletic administrators. The recent findings about both the short and long term consequences of head injuries has brought this issue to the forefront in athletic administration. Legislation has also increased awareness related to providing concussion education to coaches, parents and participants.

\section{Risk Minimization and Safety}

Issues. Although student-athletes have the responsibility to look out for their own safety, ultimately all responsibility within athletic facilities begins with the athletic administrator. The athletic administrator does share in the responsibility in hiring all coaches and athletic trainers, and are legally responsible for the safety of all studentathletes during the duration of their athletic seasons (Armenta, 2011; Aquila, 2008; Blackburn et al., 2013). The majority of high schools, including both public and private classifications, do not employ an athletic trainer (Pike et al., 2017; Pryor et al., 2015). Considering the multitudes of injuries during all athletic seasons throughout the country, athletic administrators would do well to have qualified medical personnel on staff (Rechel et al., 2008). Furthermore, coaches often are not certified to care for medical injuries of their student-athletes, which increases the need to hire athletic trainers (Dewitt et al., 2012).

The findings of the current study is in agreement with the literature, in that safety of student-athletes is at the forefront of interscholastic sports. The executive secretary of a state association states, "It is really about student-athletes safety. It is concern for the student-athletes which drives our programs." A member of the national association goes on to say:

Risk minimization is at the center of the professional development that is provided to our athletic administrators at the state and national level. There are inherent risks in participating in athletics and it is the role of the each of us involved in interscholastic sports to do what we can to limit the dangers that our athletes face on a daily basis.

Furthermore, another interscholastic administrator went on to say, "Educating athletic administrators nationwide about risk management concerns continues to be a goal of the NIAAA and its Leadership Training Institute."

Maintaining Education Focus.

Winning is the measure by which some shareholders quantify success in inter- 
scholastic sports. It is the mission of interscholastic athletic administration to ensure that high school athletics is first and foremost considered to be the other half of education, providing student-athletes a learning experience that is on the playing field rather than the classroom (Gardner, 2015; Johnson et al., 2017). Gardner and Van Erk (2011) also have a message that goes beyond winning, in that all shareholders of interscholastic sports should be preparing student-athletes beyond victories they have earned in interscholastic sports.

This also applies to student-athletes that often compete on clubs sport teams. Many student-athletes have favored the club sport team than their high school sport team. As a result, many state associations that serve as the governing body for interscholastic sports have reluctantly mandated policies playing for both club and school team at the same time. One reason is that the opposing programs; club versus school, have opposing athletic philosophies. Club sports focuses too much on winning; whereas, school sports focuses more on education-based athletics (Coach \& AD, 2010; Hums \& MacLean, 2013; Hyland, 2008; Pennington, 2003). Reluctantly, many times the student-athlete will choose the club sport team.

The findings of this research study are once again in agreement with previous research, in that maintaining an educational focus is at the core of interscholastic sport programs throughout the country, and that responsibility lies with athletic administrators. An interviewee from a high school athletic association has this to say about education-base athletics:

Across the country, high school sports are being threatened by various levels of "club sports" which seek to provide a more elite experience for those participants. It is important that as high school athletic administrators we continually emphasize the benefits of education-based athletics. The responsibility for ensuring that our programs keep an educational focus rests with the athletic administrator and the coaches they employ. A high-level administrator has the last word on the importance of all athletic administrators becoming educated and certified as they lead their education-based athletic programs:

The NIAAA is the source for both the support and preparation of those leading education-based athletic programs. Accredited by AdvancEd and North Central Association Commission on Accreditation and School Improvement, the NIAAA has developed an educational curriculum, and a certification program, specific to meet the needs of the interscholastic athletic administrator.

After considering the pertinent issues surrounding interscholastic sports, as well as the implications these issues are to practicing athletic administrators, the authors would like to give an interscholastic executive director the final word about the position of the athletic administrator and the significance of this study: 
Preparation and commitment to lifelong learning are the prerequisites for interscholastic athletic administration in today's world. Service to student-athletes, instructing coaches in areas outside of sports specific knowledge, and making decisions that keep the school district and its educational leaders exposed to as little as possible litigation are personal qualities desired. Providing safe and plentiful participation opportunities, as well as the commitment to the best educational opportunities for students, is the goal of the highly qualified athletic administrator. The enormity of the position responsibilities makes it imperative that the person leading the program has an understanding of the NIAAA. The surveyed items in this study verify the need for preparation in areas affiliated with participation in school based sports.

\section{Programmatic Recommendations}

Now that all three propositions have been answered, one final question remains ... Where to go from here? The following discussion section provides suggestions as to how the MSHSL executive board, NDIAAA membership, NIAAA membership, and other interscholastic stakeholders can evaluate programmatic goals based on findings of the current study. Possible directions include the NIAAA leadership training program, new course developments, state associations, and collaboration between NIAAA regional sections.

\section{NIAAA Leadership Training}

Program. The leadership training program, also known as the certification program, is designed to better prepare future, as well as current athletic administrators tackle the training and preparation needed when engaging the complexity of this challenging, yet rewarding profession (Forsyth, 2015). Currently there are five certification levels: a) registered athletic administrator, b) registered middle school athletic administrator, c) provisional certified athletic administrator, d) certified athletic administrator, and e) certified master athletic administrator. The primary goal of the leadership training program is a self-improving program to better serve the administrator's school, district, community, and the profession (NIAAA, 2019).

The leadership training curriculum currently consist of 47 courses with a focus on foundational, operation management, and leadership concepts. Foundational courses are designed to cover legal issues, philosophy of interscholastic sports, share-holders professional development, and budgeting and finance strategies. Operation management courses are designed to cover field and equipment management, contest management, management, marketing, and technology. Leadership courses are designed to cover personnel issues, assessment issues, as well as other administrative issues (NIAAA, 2019).

Administration issues rated in the current investigation: Athletic Facilities, 
Educational Focus, Online Registration, Transfer Issues, and Travel Teams are considered operation management issues within the operation management curriculum. Furthermore, issues related to sports medicine: Athletic Training, Concussions, Health Issues, Risk Management, and Safety Issues are also addressed within the operation management curriculum. Therefore, it is within the operation management courses the authors believe the current research investigation can have a direct impact.

New Course Developments. The leadership training curriculum currently consist of two courses titled "Athletic Administration: Current Issues in American Sports." LTC 710-A course description includes topics such as: Dealing with Parents, Athletic Director Burnout, Ethics \& Media Relations, Retaining Coaches, and Technology. LTC 710-B course description includes topics such as: Booster Clubs, Home Schooling, Hazing, Specialization, Performance Enhancing Substances, and Equity Issues.

The authors would like to propose two possible directions. First, address the issues discussed in the current investigation on a rotating basis. In other words, during odd number years LTC 710-A would include issues as currently being offered, and on even number years include issues rated in the current investigation; Athletic Facilities, Educational Focus, Online Registration, Transfer Issues, and Travel Teams. The same for LTC 710-B; that is, rotating issues on odd versus even number years. During odd number years include issues as currently being offered; whereas, during even number years include issues rated in the current investigation; Athletic Training, Concussions, Health Issues, Risk Management, and Safety Issues.

Second, results from the current study indicate that it is worthy of considering development of two addition courses titled "Athletic Administration: Current Issues in American Sports"; however, numbered LTC 710-C and LTC 710-D. LTC 710-C course description would include the following issues from the current investigation: Athletic Facilities, Educational Focus, Online Registration, Transfer Issues, and Travel Teams. LTC 710-D course description would include the following issues from the current investigation: Athletic Training, Concussions, Health Issues, Risk Management, and Safety Issues. Once again, the authors believe the current research investigation can have a direct impact.

State Associations. The NDIAAA served as the pilot for the current investigation. Although the current investigation also includes findings from a national sample, other state associations could follow in replicating NDIAAA's lead. The national findings could serve as a benchmark; however, just as the NDIAAA now has a comparison study in which to weigh administration issues, the other state associations could also have their own comparison study to weigh administration issues among their own state membership.

Under the current investigation, Concussions, Maintaining Educational Focus, Risk 
Minimization, and Safety Issues were rated relatively the same as the pilot study; very high importance. Beyond these top four issues, the remaining six issues did vary between the two samples; important to somewhat important. Therefore, it is conceivable the other 50 state associations rating some administration issues relatively the same as the national sample, and the remaining administration issues differently. The authors do believe such comparison studies would allow individual state associations a data set in which to derive future directions for their respective memberships.

NIAAA Regional Sections. The national sample allowed the data to be evaluated across regional sections (see Table 3). Four issues were found to be significant across regional sections; $A$ thletic Facilities, Athletic Training, Health Issues and Travel Teams (see Tables 3). Although reasons as to why these issues were found to be significant goes beyond the scope of the authors pursuit; however, these findings does bring into question ... Why?

Athletic facilities appears to be a significant importance to region 6 which includes Arkansas, Colorado, New Mexico, Oklahoma, and Texas. What decisions and practices are being made regarding athletic facilities? Given the number of interscholastic football facilities being built within this region, one might assume athletic facilities would be a significant factor. A discussion among the NIAAA section leaders could bring to the forefront why. The same can be said regarding the other significant issues across regional sections (see Table 4).

\section{Conclusion}

This investigation has helped fill the gap regarding a comprehensive study in identifying administration issues relevant to the day-to-day operation of interscholastic sport programs. The current investigation identified administration issues that are pertinent within interscholastic sports today, as well as the next five years. Given the lack of research on interscholastic sport, the current investigation is warranted considering the enormous size and scope of this important sport segment. The current research offers an exciting foundation from which many stakeholders can benefit; athletic administrators, superintendents, principals, coaches, parents, and student-athletes.

Athletic administrators, as well as researchers alike, can use the issues identified in this study to validate procedures, guidelines and strategy for policies, educational purposes, and additional research. More specific, it is the assertion of the authors that Concussions - highest rated issue in this investigation - be a top priority. As proposed in the programmatic recommendations, NIAAA leadership training program can help meet this priority by offering a stand-alone curricular course, or be included alongside other issues also found to be rated very high to high importance. 


\section{Limitations}

Although the current study can be considered groundbreaking as it is the first of its kind to gauge administrators' perceptions of the relevant issues facing high school sport, there are a few limitations to the study. Both the quantitative and qualitative components of the study were cross-sectional in nature. Therefore, findings do not offer the ability to track longitudinal analysis of these issues. Also, the NIAAA national convention typically hosts approximately 1,200 athletic administrators per year from around the country. With over 24,000 high schools across the country, not all athletic administrators are able to attend this national conference. Many athletic administrators might not have attended that are representatives of smaller high schools having less resources for professional development; attending a national conference. It is also conceivable that athletic administrators from larger high schools might not have attended this national conference due to personal reasons. Therefore, athletic administrators representing their respective sections might have been unable to attend this annual convention. Thereby, only those athletic administrators that were present during their respective section business meeting would have completed the survey questionnaire. It is also possible that some athletic administrators that were present may have elected not to participate. Nonetheless, the authors are very pleased to have received a total of $(\mathrm{N}=$ 170) completed surveys.

\section{Recommendations for Further Research}

The authors are aware the current investigation did not identify an exhaustive list of pertinent administration issues within interscholastic sports. A follow-up study is warranted to identify other administration issues sought to be pertinent in the interscholastic sports arena. As the authors alluded to earlier, determining why sectional differences exist among administration issues went beyond the scope of the current study. Therefore, additional studies are warranted to better understand why these significant differences existed. One possible approach could be case studies that consist of states belonging to the regions where significant differences exist. Finally, interviews can serve to add valuable context to the issues that data analysis alone does not provide. Therefore, interviews among other experienced athletic administrators local, district, state, and national levels to confirm the findings of the current study, as well as additional issues that are pertinent in interscholastic sports, are encouraged.

\section{References}

Aldret, R.L. (2018). Identification of essential skills for entry-level athletic trainers using the Delphi method. Performance Improvement, 57(1), 27-38. Andrew, D.P.S., Pedersen, P.M., \& McEvoy. (2011). Research methods and design in sport management. Champaign, IL: Human Kinetics. 
Aquila, F. D. (2008). School law for K-12 educators: Concepts and cases. Thousand Oaks, CA: Sage Publications.

Armenta, T. (2011). Playing it smart: Safety in extracurricular activities. The Cleaning House, 84, 155-159.

Bailey, R. (2006). Physical education and sport in schools: A review of benefits and outcomes. The Journal of School Health, 76(8), 397-401. doi: 10.1111/j.1746-1561.2006.00132.x

Bell, A., Dorsch, K. D., McCreary, D. R., \& Hovey, R. (2004). A look at nutritional supplement use in adolescents. Journal of Asolescent Health, 34(6), 508-516. doi: 10.1016/j. jadohealth.2003.07.024

Bey, T., \& Ostick, B. (2009). Second impact syndrome. The Western Journal of Emergency Medicine, 10(1), 6-10.

Blackburn, M., Forsyth, E., Olson, J., \& Whitehead, B. (2013). NLAAA's guide to interscholastic athletic administration. Champaign, IL: Human Kinetics Branch, D., \& Crow, R.B. (1994). Intercollegiate athletics: Back to the Future? Sport Marketing Quarterly, 3, 13-21.

Carman, A. J., Ferguson, R., Cantu, R., Comstock, R. D., Dacks, P. A., \& DeKosky, S. T. (2015). Mind the gapsAdvancing research into short-term and long-term neuropsychological outcomes of youth sports-related concussions. Nature Reviews Neurology, 11(4), 230-245.

Castrucci, B.C., Gerlach, K.K., Kaufman, N.J., \& Orleans, C.T. (2004). Tobacco use and cessation behavior among adolescents participating in organized sports. American Journal of Health Behavior, 28(1), 63-71.

Centers for Disease Control and Prevention (2017a). Sports and recreation-related injuries. Retrieved from: https:// www.cdc.gov/healthcommunication/ toolstemplates/entertainmented/ tips/SportsInjuries.html

Centers for Disease Control and Prevention (2017b). Health and Academics. Retrieved from https://www.cdc. gov/healthyoutth/health_and_academics

Centers for Disease Control and Prevention. (2009). Nonfatal traumatic brain injuries related to sports and recreation activities among persons aged $\leq 19$ years, United States, 2001-2009. Morbidity and Mortality Weekly Report, 60(39), 1337-1342.

Chorosiewski, K., \& Whitten, F. (2009). Managing the growing pains of facility additions of renovations. Interscholastic Athletic Administration, 35(3), 18-19.

Coach \& A.D. (2010, October). Select team coaches vs. high school coaches. Retrieved from https://coachad.com/articles/ select-team-coaches-vs-high-schoolcoaches/

Davies, S., Coxe, K., Harvey, H.H., Singichetti, B., Guo, J., \& Yang, J. (2018). Qualitative evaluation of high school implementation strategies for youth sports concussion laws. Journal of Athletic Training, 53(9), 873-879.

Denzin, N. K., \& Lincoln, Y. S. (2018). The SAGE handbook of qualitative 
research (5th ed.). Thousand Oaks, CA; Sage.

Diehl, K., Thiel, A., Zipfel, S., Mayer, J., Litaker, D. G., \& Schneider, S. (2012). How healthy is the behavior of young athletes? A systematic literature review and meta-analyses. Journal of Sports Science \& Medicine, 11(2), 201220.

DePadilla, L., Miller, G.F., Jones, S.E., Peterson, A.B., \& Breiding, M.J. (2018). Self-reported concussions from playing a sport or being physically active among high school students- United States, 2017. Morbidity and Mortality Weekly Report, 67(24), 682-685.

Dewitt, T. L., Unruh, S. A., \& Seshadri, S. (2012). The level of medical services and secondary school-aged athletics. Journal of Athletic Training, 47(1), 9195.

Dodge, T. L., \& Jaccard, J. J. (2006). The effect of high school sports participation on the use of performance enhancing substances in young adulthood. Journal of Adolescent Health, 39(3), 367-373. doi: 10.1016/j. jadohealth.2005.12.025

Doleschal, J.K. (2006). Managing risk in interscholastic athletic programs: 14 legal duties of care. Marquette Sports Law Review, 17(1), 295-339.

Drain, T. S., \& Ashley, F. B. (2000). Back to the future II: A comparison with Branch and Crow five years later. Sport Marketing Quarterly, 9, 77-84.

Forsyth, E. (2015). National Interscholastic Athletic Administrators Association. In Dodds, M. \& Reese Jr., T.,
Sports Leadership: A Concise Reference Guide (pp.163-164). Santa Barbara, CA: Mission Bell Media.

Forsyth, E., Martin, T. \& Whisenant, W. (2018). Interscholastic athletics. In Pedersen, P. M., \& Thibault, L. (Eds.), Contemporary Sport Management (pp. 142-166). Champaign, IL: Human Kinetics.

Forsyth, E., \& Olson, J. (2013). Challenges in Today's Interscholastic Sport Administration. In Blackburn, M., Forsyth, E., Olson, J. \& Whitehead, B., NLAAA's Guide to Interscholastic Athletic Administration (pp. ix-xvi). Gard, A.N. (2017). High school academics: Increasing the standard. The Physical Educator, 74(1), 405-419.

Gardner, B. (2015). Defining education-based activity programs. NFHS. Retrieved from https://www. nfhs.org/articles/defining-education-based-activity-programs/

Gardner, R. B., \& Van Erk, N. (2011). Standards for measuring success not based on number of victories. High School Today, 1, 1-3.

Granitto, M.H., \& Norton, C. (2018). Concussion: Prevention, assessment, and management. American Nurse Today, 13(2), 16-20.

Green, L. (2015, May 20). Top ten sports law issues impacting school athletics programs. Retrieved from https:// www.nfhs.org/articles/top-tensports-law-issues-impacting-schoolathletics-programs/

Hills, A. (1998). Scholastic and intellectual development and sport. In K. M., 
\& Chan, L. Micheli (Eds.), Sports and Children (pp. 76-90). Champaign, IL: Human Kinetics.

Hums, M. A., \& MacLean, J. C. (2013). Governance and policy in sport organizations. Scottsdale, AZ: Holcomb $\mathrm{Ha}$ thaway.

Hyland, D. A. (2008). Paidia and paideia: The educational power of athletics. Journal of Intercollegiate Sport, 1(1), 66-71. doi:10.1123/jis.1.1.66

Jochimek, M., Krokosz, D., \& Lipowski, M. (2017). Physical activity and sport as a protective factor against health-threatening experiments with adulthood. Baltic Journal of Health and Physical Activity, 9(3), 112-124. doi: 10.29359/BJHPA.09.4.09

Johnson, J. E., Giannoulakis, C., \& Scott, B. F. (2017). Interscholastic competitive balance: An examination of state athletic association administrators. Journal of Sport Management, 31, 256274. doi: 10.1123/jsm.2016-0226 Johnson, J. E., Lower, L. M., Scott, B. F., \& Manwell, A. K. (2018). The public/private divide: An analysis of American law relative to recruiting and transfer policies in interscholastic athletics. International Journal of Sport Policy and Politics, 10(3), 493-508. doi: 10.1080/19406940.2018.1428214

Kreager, D.A. (2007). Unnecessary roughness? School sports, peer networks, and male adolescent violence. American Sociological Review, 72(5), 705724.

Langlois, J. A., Rutland-Brown, W., \& Wald, M. M. (2006). The epidemiol- ogy and impact of traumatic brain injury: A brief overview. The Journal of Head Trauma Rehabilitation, 21(5), 375-378. doi: 10.1097/00001199200609000-00001

Lipowski, M., \& Bieleninik, L. (2014).

Personality superfactors and healthy behaviors of professional athletes. Current Issues in Personality -Psychology, 2(2), 57-67. doi: 10.5114/ cipp.2014.44302

Maxwell, S.E., \& Delaney, H.D. (1991). Designing experiments and analyzing data: A model comparison perspective. Journal of the American Statistical Association, 86(413), 247-248.

McGuine, T.A., Pfaller, A.Y., Post, E.G., Hetzel, S.J., Brooks, A., \& Broglio, S.P. (2018). The influence of athletic trainers on the incidence and management of concussions in high school athletes. Journal of Athletic Training, 53(11), 1017-1024.

Meier, K.J., Eller, W.S., Marchbanks, M.P., Robinson, S., Polinard, J.L., \& Wrinkle, R.D. (2004). A lingering question of priorities: Athletic budgets and academic performance revisited. Review of Policy Research, 21(6), 799-807.

Moser, R. S., Schatz, P., \& Jordan, B. D. (2005). Prolonged effects of concussion in high school athletes. Neurosurgery, 57(2), 300-306. doi: 10.1227/01. NEU.0000166663.98616.E4

National Athletic Trainers' Association (2017). Quick Facts. Retrieved from https://www.nata.org/nata-quickfacts 
National Federation of State High School Association (2018). 2016-17 High school athletics participation survey results. Retrieved from http:/ /www. nfhs.org/Participation-Statistics/ PDF/2016-17_Participation_Survey_Results.pdf

NIAAA. (2019). NIAAA certification program. Retrieved from www.niaaa. org/niaaa-programs/niaaa-certification-program

Palmero, M., Dotterweich, A., Lhotsky, G., \& Walker, J. (2012). Risk management plans: Existence and enforcement at NIAAA member high school athletic departments. Sport Journal, 15(1), 1-16.

Pennington, B. (2003, November 12) As team sports conflict, some parents rebel. The New York Times. Retrieved from http://www.nytimes. com/2003/11/12/sports/as-teamsports-conflict-some-parents-rebel. html

Peretti-Watel, P., Guagliardo, V., Verger, P., Pruvost, J., Mignon, P., \& Obadia, Y. (2003). Sporting activity and drug use: Alcohol, cigarette, and cannabis use among elite student athletes. $A d$ diction, 98(9), 1249-1256.

Pike, A. M., Pryor, R. R., Vandermark, L. W., Mazerolle, S. M., \& Casa, D. J. (2017). Athletic trainer services in public and private secondary schools. Journal of Atbletic Training, 52(1), 5-11. doi: 10.4085/1062-6050-51.11.15 Pryor, R. R., Casa, D. J., Vandermark, L. W., Stearns, R. L., Attanasio, S. M., Fontaine, G. J., \& Wafer, A. M.
(2015). Athletic training services in public secondary schools: A benchmark study. Journal of Athletic Training, 50(2), 156-162. doi: 10.4085/10626050-50.2.03

Rechel, J. A., Yard, E. E., \& Comstock, R. D. (2008). An epidemiologic comparison of high school sports injuries sustained in practice and competition. Journal of Athletic Training, 43(2), 197-204. doi: 10.4085/1062-605043.2.197.

Robinson, M., Hums, M., Crow, R. \& Philips, D. (2001). Profiles of sport industry professionals: The people who make the games happen. Burlington, MA: Jones and Bartlett Learning. Schneider, K., Meeteer, W., Nolan, J.A., \& Campbell, H.D. (2017). Health care in high school athletics in West Virginia. Rural and Remote Health, 17(1), 1-11.

Taliaferro, L.A., Rienzo, B.A., \& Donovan, K.A. (2010). Relationships between youth sport participation and selected health risk behaviors from 1999-2007. Journal of School Health, 80(1), 399-410.

van den Berg, P., Neumark-Sztainer, D., Capri, G., \& Wall, M. (2007). Steroid use among adolescents: Longitudinal findings from project EAT. Pediatrics, 119(3), 476-487.

Wallace, J., Covassin, T., \& Beidler, E. (2017). Sex differences in high school athletes' knowledge of sport-related concussion symptoms and reporting behaviors. Journal of Athletic Training, 
52(7), 682-688. doi: 10.4085/10626050-52.3.06

Weber, M. L., Welch, C. E., \& Parsons, J. T. (2014). School nurses' familiarity and perceptions of academic accommodations for student-athletes following sport-related concussions. The Journal of School Nursing, 31(2), 146-154. doi: 10.1177/1059840514540939

Whisenant, W. \& Forsyth, E. (Chapter 8). Interscholastic sports. In Pedersen, et al. (2011, 4th Edition). Contemporary Sport Management. Champaign, IL: Human Kinetics. pp. 164-185.

Whisenant, W. Forsyth, E. \& Martin, T. (Chapter 7). Interscholastic sports. In Pedersen, et al. (2014, 5th Edition). Contemporary Sport Management. Champaign, IL: Human Kinetics, pp. 162189.
Williams, R. M., Welch, C. E., Parsons, J. T., \& Valovich, T. C. (2015). Athletic trainers' familiarity with and perceptions of academic accommodations in secondary school athletes after sport related concussions. Journal of Athletic Training, 50(3), 262-269. doi: 10.4085/1062-6050-49.3.81

Willis, H.R. (2016). AAU basketball-participants'perceptions of their $A A U$ experience. (Unpublished Master's thesis). Eastern Illinois University, Illinois, USA.

Windsor, S. (2018, January 21). Thomas Kithier saga begs the question: What should be done about the transfer rule? USA Today. Retrieved from http:/ / usatodayhss.com/2018/thomas-kithier-saga-begs-question-whatshould-be-done-about-transfer-rule 